\title{
Opinion
}

\section{The Importance of Teaching and Fostering Clinical Research in Primary Health Care}

\author{
Gerald L. Klein, MD'*; Mark A. Brown, PhD² \\ 'MedSurgPI, LLC, Raleigh, NC, USA \\ ${ }^{2}$ Department of Clinical Science, Colorado State University, Fort Collins, CO 80523, USA \\ ${ }^{*}$ Corresponding author \\ Gerald L. Klein, MD \\ Principal, MedSurgPI, LLC, Raleigh, NC, USA; E-mail: gklein@medsurgpi.com
}

\section{Article information}

Received: January $7^{\text {th }}$, 2021; Revised: February 16 $6^{\text {th }}, 2021$; Accepted: February 18 $8^{\text {th }}, 2021$; Published: February 19 $9^{\text {th }}, 2021$

\section{Cite this article}

Klein GL, Brown MA. The importance of teaching and fostering clinical research in primary health care. Clin Trial Pract Open J. 202I; 4(I): I3-I5. doi: $10.17 \mid 40 /$ CTPOJ-4-119

\begin{abstract}
T $t$ is important for primary health care (PHC) teaching institu1 tions and hospitals to create an atmosphere fostering clinical investigation for all health care practitioners (HCP). ${ }^{1}$ This involves not just clinical trials, but observations, examinations, and investigations are a critical part of the education of any health science students. $^{2}$ This is the basis of science. Without knowing how to apply a scientific thought process and methodology to a clinical situation, it will prevent one from reaching their optimum abilities. Easy-to-conduct, practical single subject studies also known as N-1 clinical trials, can help lead to modifying a patient's therapy, new practice patterns, therapeutic improvements, and increasing students skills. ${ }^{3}$ These single subject studies (N-1) are multiple cross-over trials involving the same single patient. Implementing clinical investigations into HCPs work routine, can make them more passionate about their work, prevent burnout, and lead to new products and services.
\end{abstract}

In higher education, the employment of pedagogical methods such as clinical investigation is a key element of mentored inquiry and experiential learning. Among high impact educational practices, ${ }^{4,5}$ mentored inquiry and experiential learning have been shown to have the most positive effects with regard to promoting student engagement and future success as a practitioner. ${ }^{4-7}$ There is increasing evidence indicating that students who are involved in experiential learning as part of their training achieve higher academic performance, exhibit higher rates of retention and, ultimately, outperform their peers as professionals. ${ }^{7-11}$ Experiential learning is particularly well-suited for bridging intersecting disciplines in highly complex fields like medicine., ${ }^{40,12}$

Understanding clinical investigations is one of the key ingredients for primary care HCPs to knowing how to interpret the scientific literature and how to read and critically review scientific publications. It improves scientific literacy, and it helps make better clinical decisions. ${ }^{13}$

Clinical investigations can be undertaken throughout peoples career if an inquisitive attitude is maintained. The following examples provide a few practical ways of accomplishing this for physicians, physician assistants (PA), nurse practitioners (NP), pharmacists, respiratory therapists (RT), veterinarians, and respiratory biomedical researchers.

\section{Physicians}

- What percent of patients wear a hat when they walk or jog outside?

- What percent of geriatric patients are willing to take age recommended vaccines such as for pneumonia and herpes zoster? What percent of minority patients?

- How to Improve medication adherence with digital devices?

- Is there a correlation between metabolic markers and sleep apnea?

\section{Nurses}

- Ask your patients if they are taking vitamins and supplements, Which ones and why?

- Least painful area to apply injections in the geriatric population?

- What percent of patients do not understand what was discussed at their medical visit?

- How to increase the percentage of patients who will schedule their prescribed testing?

- How to increase follow-up appointments? 


\section{Pharmacists}

- Record if the patients are refilling their medication on time?

- Do patients know the side effects of their medication? Which type medications do they least understand?

- What percentage of people believe that if their medication has to be taken three times a day, that they should wake up at night and take the third dose at that time?

\section{Physician Assistants/Nurse Practitioners}

- How to use classical prescription antihistamines for sleep aids?

- What type of exercise regime will your patients adhere to? Is this affected by gender, age, race, income, or education?

- How to time peak antihypertension medication peak levels with a patient's most frequent hypertensive time of the day?

- How to improve patient communications?

\section{Respiratory Therapists}

- What patients benefit from nebulized bronchodilators?

- How to increase adherence in geriatric patients who have sleep apnea?

- How to use inhaled bronchodilators effectively as prophylactic medication?

- Is auscultation directly on the skin more accurate than through a garment?

\section{Veterinarians}

- How to prevent dogs from having separation anxiety?

- Should certain dog or cat breeds be taking supplemental vitamins?

- How to increase the adherence of injecting subcutaneous medication for pets?

\section{Biomedical Researchers}

- How might a new discovery be clinically relevant?

- What are the potential off-label applications of existing commercial therapeutics?

- For a therapeutic in development, does it alleviate existing health disparities or provide particular benefit to underserved populations?

One of the inappropriate assumptions that many primary healthcare academic institutions and other institutions make is that it is not their role to teach or encourage research. However, it is essential in their understanding of what evidence-based medicine consists of and how to interpret data. ${ }^{14}$ The objective observation and recording of clinical data is an essential element of all healthcare. This observation can then be made into an assumption that could be scientifically tested and may find its way into clinical practice. An example of this was from my former allergy practice. It was difficult to get toddlers and young children to take a forced expiration to try and hear wheezing. When a pinwheel was placed before them, they would blow on it, creating a forced expiration and made it easier to discern wheezing. A small clinical study demonstrated the efficacy of this technique. ${ }^{15}$ Small inexpensive studies such as this improved the physician's skills and improved the patient experience.

Teaching a basic course on clinical investigation that covers basic aspects of the following would help encourage these types of inquiries.

- Basic statistics for clinical studies

- Regulations for human or animal clinical trials essential documents required for a clinical trial When is an informed consent and Investigational? review board (IRB) required for a clinical trial?

- How to do hypothesis testing?

- Essentials of a scientific manuscript?

Primary healthcare institutions will benefit greatly from encouraging and supporting their students to be more involved in clinical research and to publish their findings.

\section{CONFLICTS OF INTEREST}

The authors declare that they have no conflicts of interest.

\section{REFERENCES}

1. Hatfield LA, Kutney-Lee A, Hallowell SG, Guidice MD, Ellis LN, Verica L, et al. Fostering clinical nurse research in a hospital context. J Nurs Adm. 2016; 46: 245-249. doi: 10.1097/ NNA.0000000000000338

2. Apel J. On the meaning and the epistemological relevance of the notion of scientific phenomena. Synthese. 2011; 182: 23-38. doi: 10.1007/s11229-009-9620-y

3. Nikles C. An n-of-1 trial service in clinical practice: Testing the effectiveness of stimulants for attention-deficit/hyperactivity disorder. Pediatrics. 2006; 117(6): 2040-2046. doi: 10.1542/peds.20051328

4. Kuh G, Kinzie J. What Really Makes a 'High-Impact' Practice High Impact? Inside Higher Education. 2018.

5. Kuh GD. Student Success in College: The Promise of High Impact Practices. 2011.

6. Tinto, V. Completing College: Rethinking Institutional Action. Chicago, USA: The University of Chicago Press; 2012.

7. Pascarella ET, Seifert TA, Whitt EJ. Effective instruction and college student persistence: Some new evidence. In: Braxton JM, ed. The Role of the Classroom in College Student Persistence (New Directions for Teaching and Learning). San Francisco, USA: 2008; 115: 55- 
and professional development. Science Education. 2006; 91: 36-74.

8. Boyd MK, Wesemann JL. Broadening Participation in Undergraduate Research: Fostering Excellence and Enhancing the Impact. Washington, DC, USA: Council on Undergraduate Research; 2009.

9. Taraban R, Blanton RL. Creating Effective Undergraduate Research Programs in Science - The Transformation from Student to Scientist. New York, USA: Teachers College Press; 2008.

10. Kuh GD, Kinzie J, Schuh JH, Whitt EJ. Student Success in college: Creating Conditions that Matter. San Francisco, USA: Jossey-Bass; 2005.

11. Hunter AB, Laursen SL, Seymour E. Becoming a scientist: The role of undergraduate Research in students' cognitive, personal,

12. Itin CM. Reasserting the philosophy of experiential education as a vehicle for change in the 21st century. The Journal of Experiential Education. 1999;.22(2): 91-98. doi: 10.1177/105382599902200206

13. Hernandez LV,. Gerson LB. A guideline for reviewing a clinical research paper. Gastrointest Endosc. 2015; 82(2): 233-236. doi: 10.1016/j.gie.2015.05.015

14. Jamjoom A. Research and audit. Sdt BMJ. 2009; 17: 62-63.

15. Klein GL, Ziering RW. The pinwheel a diagnostic tool to detect wheezing in young children. Pediatric Allergy Asthma \& Immunology. 1989; 3(1): 37-39. doi: 10.1089/pai.1989.3.37 